\title{
Significados identificacionais: ethos e espaço político na constituição discursiva da realidade social feminina
}

\author{
Identificational meanings: ethos and political space in the \\ discursive constitution of feminine social reality
}

Dulce Elena Coelho Barros

(Universidade Estadual de Maringá)

\section{RESUMO}

O aporte teórico-metodológico deste estudo é tomado da vertente faircloughiana de Análise de Discurso Crítica. Com base em Fairclough (2003), que concebe o discurso na confluência de três práticas, quais sejam, as práticas linguística, discursiva e social, as análises aqui empreendidas se voltam para práticas discursivas de parlamentares que ocupam o espaço sociopolítico do Parlamento Nacional brasileiro para abordarem o tema "mulher". O ethos dos atores politicos envolvidos nessa prática é discutido a partir dos significados identificacionais, dimensão analítica que, ao lado dos significados acionais e representacionais, se faz presente no modelo teórico-metodológico criado por Fairclough para análise de texto numa perspectiva social. A natureza argumentativa dos textos a partir dos quais foram extraídos os dados deste estudo, mostrou-se propícia à inclusão de aspectos abordados por Aristóteles (2000) em sua Retórica das Paixões, tais como cólera, calma e favor, categorias que, entre outros fatores, se coadunam com modos particulares de ser (identidades sociais pessoais) focalizados neste artigo. Em consonância com a proposta de discutir o espaço político da constituição discursiva da realidade social feminina, lanço mão daquilo que Charaudeau (2006) denomina de lugares de fabricação do discurso político, a saber, um lugar de governança, um 
lugar de opinião e um lugar de mediação. O estudo demonstra que a prática discursiva parlamentar sofre influências do contexto institucional da produção textual, no seio do qual o tratamento de temas relativos aos sujeitos sociais femininos se converte em instrumento útil ao agir parlamentar, bem como ao funcionamento e atuação das ideologias sobre o mundo da vida daquelas que se vêem nela representadas.

Palavras-chave: análise de discurso crítica; argumentação; ethos político.

\section{ABSTRACT}

Current analysis is based on the theoretical and methodological stance of the Faircloughian trend in Critical Discourse Analysis. Fairclough (2003) conceives discourse within the confluence of three types of practice, namely linguistic, discursive and social practice. Analyses discussed in this research refer to discursive practices of members of the Brazilian parliament who occupy this social and political space to take up themes on 'the female'. The ethos of the political agents involved in such a practice is debated from identificational meanings. It is actually an analytic dimension which, besides actional and representational meanings, is present in Fairclough's theoretical and methodological model for text analysis within the social perspective. The text's arguments from which data in current study have been extracted are highly favorable to the inclusion of aspects investigated by Aristotle (2000) in his Rhetoric of the Passions, such as anger, calmness and grace. They are categories which, among others, fit into particular modes of being (social and personal identities) which are focused in current article. Discussing the political space of the discourse constitution of the feminine social reality, the article introduces Charaudeau (2006) who calls the above the fabrication sites of political discourse, or rather, a place of government, opinion and mediation. The study has showed that the parliamentary discursive practices is affected by the institutional context of the textual production, where the female themes is converted into a profitable tool for the parliamentary action, as so for the actuation of the ideologies upon the world life of the females represented in these practices.

Key-words: Critical discourse analysis; argumentation; political ethos; situational context. 


\section{Palavras iniciais}

Sob o ponto de vista da Análise do Discurso Crítica, é por meio dos significados identificacionais que se pode ter acesso aos modos pelos quais os atores sociais emergem dos textos. Sem deixar de abordar os textos como multifuncionais, Fairclough (2003:26-28) investe em uma distinção que privilegia tipos de significação gerados na confluência da ação, representação e identificação. Essa perspectiva de análise, que visa olhar o texto com maior foco nas significações que ele comporta, traz uma perspectiva social para o âmago do texto. Os modos de agir (significados acionais), os modos de representar (significados representacionais) e os modos de ser (significados identificacionais), nada mais são do que práticas sociais que figuram, respectivamente, como 'parte da ação', nas representações que sempre são partes de práticas sociais e como constituição de modos particulares de ser (identidades sociais pessoais). Fairclough (2003:28) aproxima a sua reflexão dos três eixos distinguidos por Foucault (1994:318) para a análise dos aspectos do sentido na linguagem, permitindo ver que: a) destacar os significados acionais, compreende focalizar as funções interpessoal e textual da linguagem, atentando-se para aspectos do sentido que incidem sobre o eixo do poder; b) destacar os significados representacionais, compreende focalizar a função ideacional ou representativa da linguagem, atentando-se para aspectos do sentido que incidem sobre o eixo do conhecimento e do controle sobre as coisas no mundo; c) destacar os significados identificacionais, compreende focalizar a função interpessoal da linguagem, atentando-se para aspectos do sentido que incidem sobre o eixo da ética.

Os significados acionais, representacionais e identificacionais correspondem aos seguintes elementos das ordens de discurso no nível da prática social: gêneros, discursos e estilos. Essa correspondência entre ação e gêneros, representação e discursos, identificação e estilos sugere abordar o texto como parte de eventos específicos.

No que concerne aos modos particulares de ser, os significados identificacionais lançam luz sobre as identidades sociais que se constroem na confluência do evento discursivo (o texto) com as práticas sociais. 
Ao empreender a análise do evento social em foco neste artigo, a saber, a ocupação da tribuna federal para tratamento do tema "mulher" e as práticas sociais de caráter mais abstrato que perpassam o ato de tomada da palavra nesse espaço de poder, busco realçar os significados identificacionais, muito embora as três dimensões do significado apontadas por Fairclough não sejam mutuamente exclusivas. Nesse sentido, com vistas a empreender uma aproximação mais específica entre os elementos de natureza social e os aspectos do texto, sempre que se fizer necessário, me valerei também dos outros conceitos aqui apresentados.

Respaldada pela Análise de Discurso Crítica, que concebe o discurso na confluência de três práticas, a saber, as práticas linguística, discursiva e social, esta reflexão pretende apontar e discutir algumas categorias linguísticas que, no contexto limitado desta reflexão, figurativizam os atores políticos, no sentido de determinar-lhes ethé de identificação (cf. Charaudeau, 2006).

Ao lado da categoria avaliação, a modalidade é apenas uma das muitas marcas linguísticas capazes de revelarem a maneira como o falante se relaciona com aquilo que é dito, com o objeto de seu discurso. Demonstrar envolvimento e compromissos por meio de atos de linguagem é parte de um processo mais geral de construção da identidade do falante. Fairclough (2003), ao dividir a metafunção interpessoal ${ }^{1}$ em identificacional e relacional, busca dar conta desse fato. Para o estudioso, as identidades são relacionais no sentido de que aquilo que uma pessoa é está intimamente ligado ao como a pessoa se relaciona com o mundo e as outras pessoas. No caso particular das práticas discursivas políticas, essas identidades podem ser avaliadas em termos da construção do ethos, já que, segundo Charaudeau (2006:137), "no

1. Essa função da linguagem é apresentada por Halliday (1976) ao lado de outras duas, a saber, as funções ideacional e textual. As funções da linguagem ou metafunções enunciadas por Halliday desempenham papel fundamental na teoria e método de análise sistêmicofuncional justamente por permitir entender a estrutura linguística como elemento que engloba: 1- a nossa maneira de ver as coisas ou vivenciar o mundo que nos cerca (significados ideacionais); 2- as formas de estabelecimento e manutenção das relações sociais ou interpessoais (significados interpessoais); 3- a nossa capacidade de construir textos e reconhecê-los como unidades significativas (significados textuais). Logo, cada uma dessas categorias é usada como base para explorarmos como os significados são criados e compreendidos. 
discurso político, as figuras do ethos são ao mesmo tempo voltadas para si mesmo, para o cidadão e para os valores de referência". Nos limites deste estudo, por um lado, essa questão lança luz sobre identificação social e ethos político, e, por outro, sobre identificação social e espaço político, pois aquilo que é dito (objeto de discurso) também é determinado pelo contexto situacional (campo) em que são produzidos os textos, atravessados, por sua vez, por valores de referência que entram na constituição discursiva do dito/objeto de discurso.

Para compor o corpus deste estudo, do imenso conjunto de textos que circulam no Parlamento Nacional e se referem à realidade social feminina, foram selecionados quinze discursos produzidos para serem levados ao Plenário Nacional da Câmara dos Deputados (disponibilizados em http://www2.camara.leg.br/). Desse corpus, dezoito excertos são submetidos efetivamente ao crivo da análise, sendo cinco deles produzidos por parlamentares do sexo feminino e treze por parlamentares do sexo masculino. A identidade autoral dos discursos não foi por mim revelada por questões de ética em pesquisa, sendo indicada apenas a ordem numérica de seleção dos discursos (D.P.) a partir dos quais foram gerados os dados deste estudo. Como forma de enriquecer a discussão, na primeira subseção analítica do artigo, acrescento aos dados da pesquisa um pequeno excerto retirado do Relatório Final - Seminário Internacional: Por um Brasil sem desigualdades, texto também produzido no espaço de força e poder do Parlamento Nacional.

Este artigo se apresenta composto por duas subseções analíticas. A primeira se destina ao tratamento daquilo que, aqui, denominamos de identificação social e ethos político, numa referência aos modos pelos quais os sujeitos (parlamentares) envolvidos nas práticas discursivas de natureza política constroem seus pronunciamentos parlamentares abordando em suas falas o tema "mulher". Com esse objetivo em mente, a partir de uma perspectiva crítica, em ambas subseções, busco retratar categorias liguístico-discursivas que propiciam referendar os modos de apropriação da palavra na tribuna federal e seus efeitos sobre a autorrepresentação dos/as enunciadores/as. A análise empreendida na primeira subseção se faz a partir de duas categorias modalizadoras dos enunciados, a saber, as modalidades epistêmicas e as modalidades deônticas. 
A segunda subseção analítica se volta igualmente para o ethos político. No entanto, nesse momento do estudo, me interessa abordar o ethos relativamente às coerções da situação de comunicação, ou seja, ancorado no contexto de produção dos pronunciamentos parlamentares em foco. Nessa subseção, denominada "identificação social e espaço político", a categoria ethos é posta em análise, ao lado da categoria aristotélica phatos, numa referência às grandes paixões enunciadas por Aristóteles na sua Retórica, a saber, a cólera, a calma e o favor.

\section{Identificação social e ethos político}

Nos discursos de domínio político, a palavra pode ser vista como instrumento da política social, posto que a mesma se realiza em um gênero que, sob o ponto de vista de seu caráter acional, está a serviço de propósitos ideológicos. A manifestação da palavra no espaço público do Congresso Nacional parece conferir ao enunciador certo poder regulatório sobre as relações de classe caracterizadas pelo autoritarismo social. A palavra pública se revela como um meio de promoção do bem comum. Nesse sentido, a tomada da palavra na tribuna se faz a partir de um sujeito que, de alguma maneira, marca-se naquilo que enuncia e deixa marcas do lugar a partir do qual se manifesta linguisticamente. A modalização constitui uma dessas marcas que se inserem no fenômeno mais geral da enunciação. A Análise de Discurso incorpora aos seus preceitos teórico-metodológicos as "enunciações por meio das quais os locutores, ao mesmo tempo, instituem uma certa relação com os outros sujeitos falantes e com sua própria fala que, na concepção tridimensional do discurso - acontecimento permeado pelas práticas: sociais, discursivas e linguísticas - sugerida por Fairclough (2001, 2003), o texto consiste na realização linguístico-formal da prática discursiva. A significação é, portanto, o elemento que fundamenta o processo linguístico de construção dos enunciados.

Muito apropriadamente, Meurer (2004:134) lembra que, numa análise de textos realizada com base na LSF, da qual a ADC se vale para construir o modelo tridimensional de análise dos discursos, todos os significados têm uma conexão direta com o contexto social. Em palavras do linguista brasileiro, "na LSF, portanto, não se analisa um texto unicamente em termos dos elementos lexicogramaticais. Ao 
invés disso, cada significado deve ser relacionado simultaneamente a rotinas sociais e a formas linguísticas". Sendo assim, a começar das marcas linguísticas de modalização é possível analisar os fatores que exercem coerções sobre a situação de comunicação a partir da qual se realiza um gênero específico de texto/discurso.

A alta ocorrência das formas modais, como as modalidades epistêmicas que, segundo Fairclough (2003), correspondem às trocas de conhecimento/informação, bem como as modalidades deônticas que, de acordo com o referido linguista britânico, correspondem às trocas de atividades/bens e serviços, configuram instrumento útil na análise dos significados identificacionais e dos seus efeitos enunciativos, tal como se pode constatar na sequência de excertos apresentados a seguir.

Examinemos de maneira detalhada cada um dos nove excertos selecionados para compor o primeiro bloco de dados submetidos à análise.

O excerto (1) é marcado primeiramente por uma atitude de condenação de uma prática que, ao meu ver, é sentida pelo parlamentar como peculiar, recorrente no Congresso Nacional.

Excerto (1): A luta de emancipação das mulheres é permanente e cotidiana. Por isso, não pode ser lembrada apenas num único dia do ano. (...) a eliminação das discriminações praticadas contra as mulheres não pode ser conquistada apenas no combate ideológico, mas exige o desenvolvimento de políticas especificas que ataquem diretamente as causas e manifestações da opressão e discriminação impostas às mulheres. (D.P. 1 deputado PT-BA).

A atitude de condenação do locutor frente ao fato expresso cede lugar a uma atitude de sujeito conhecedor de um estado de coisas capaz de ir ao encontro dos interesses femininos. Ao enunciar, por meio da forma linguística nominalizada, que "a eliminação das discriminações praticadas contra as mulheres (...) exige o desenvolvimento de políticas especificas...", o orador constrói uma imagem positiva dos atores do mundo político, uma imagem de sujeitos capazes de intervir sobre aquilo que afeta as mulheres, capazes de colocarem a seu favor os instrumentos de que dispõem, a saber, a criação ou "desenvolvimento de políticas específicas que ataquem diretamente as causas e manifestações da opressão e discriminação impostas às mulheres". 
As modalidades também demonstram que os discursos dos/das parlamentares são perpassados por cobranças, demandas e exigências. Isso é o que se constata nestes excertos:

Excerto (2): (...) todos precisamos lutar pelos direitos humanos, sobretudo pelos direitos das mulheres. (D.P.2 deputado PL-MG).

Excerto (3): Estamos vivendo com uma nova geração que deve refletir sobre o poder do Estado, sobre como recriar o movimento para eleger mulheres comprometidas com um Brasil mais justo, com menos corrupção. (D.P.3 deputada PFL-TO).

Excerto (4): Temos dois brasis ou mais. Há o Brasil das mulheres que conquistaram direitos e o das mulheres cujos direitos contidos na Constituição Federal e no novo Código Civil não proporcionaram nenhuma mudança na sua vida. É para este Brasil que precisamos voltar os olhos. É para essas mulheres que precisamos voltar os olhos e quebrar o silêncio. (...) A sociedade, vale dizer, precisa também ser modificada ideologicamente. (...) Precisamos ter bolsa-escola para alfabetização da mulher trabalhadora. É preciso tratar de forma diferente os desiguais. (D.P.4 deputada PT-SC)

Excerto (5): Enfim, não podemos esquecer que as diferenças de oportunidade entre homens e mulheres em nosso continente ainda são muito grandes e cabe a todos nós estarmos atentos para que não se venha a aumentar esse fosso. (...) Nós, políticos, temos obrigação de viabilizar o Estado economicamente para promover novos empregos. (D.P. 5 deputada PT-DF).

Os quatro excertos ilustram a ocorrência de modalidades que desvelam uma atitude autorreflexiva por parte dos/das oradores/as com relação ao seu papel na quebra de um autoritarismo que vitimiza a parcela feminina da sociedade. Muitas vezes, as modalidades utilizadas demonstram que a instância política falha no seu suposto papel de promotor do bem-estar feminino e gestor da vida coletiva. Isso pode ser apreciado no excerto (6) do bloco em questão:

Excerto (6): Por isso, a Convenção Interamericana para Prevenir, Punir e Erradicar a Violência contra a Mulher é um instrumento que deve transcender o formalismo e o cerimonialismo dos acordos e ganhar vida nos trabalhos, nas escolas, nos lares e nas ruas das Américas. 
(...) No campo das ações positivas, os Estados-partes devem se empenhar para promover a educação e o treinamento dos agentes policiais e judiciários, prestar serviços especializados à mulher vítima de violência. (D.P.6 deputada PFL-BA).

Note-se que os exemplos acima realçam o caráter exortativo da argumentação suasória. Os/as parlamentares aconselham aqueles para os/as quais se dirigem e apresentam propostas para o futuro. Em busca da garantia do sucesso do empreendimento oratório é que os atores políticos se apresentam como guias morais. Convém lembrar que, para Aristóteles, é ao caráter moral que o discurso deve quase todo o seu poder de persuasão.

Ao lado das demandas e exigências, reveladoras do comprometimento dos/das parlamentares com a moral, as obrigações e necessidades, aparecem, nos excertos selecionados, como ofertas de atividades/ bens e serviços, o que pode ser examinado na parte destacada do excerto (5) - (...) Nós, políticos, temos obrigação de viabilizar o Estado economicamente para promover novos empregos - e nos excertos seguintes.

Excerto (7): Então, pela sua importância, o dia 8 de março não deve ser registrado de forma simples. Devemos dar importância a esta data e nos comprometermos com a luta dessas mulheres. (D.P7 deputado PT-PR).

Excerto (8): Precisamos mobilizar a sociedade, construir um movimento nacional que mostre a cara dessas trabalhadoras e suas bandeiras. Temos lutado pelo reconhecimento da força produtiva e reprodutiva e precisamos que sejam respeitadas. (D.P.8 deputada PT-SC).

Excerto (9): Nesta data comemorativa de hoje, diante do resultado da pesquisa acima mencionada, precisamos ir além dos cartões, presentes e buquês de flores e lutar de forma mais contundente para oferecermos, como presente maior, uma reação prática e imediata contra os agressores das mulheres brasileiras (D.P. 9 deputado PL-ES).

Os excertos grifados constatam que aqueles/as que ocupam o espaço de poder no Parlamento se fazem sentir como sujeitos dispostos a agir em favor daquelas que, conforme comprovam os dados 
deste estudo, encontram-se à margem da sociedade. A meu ver, essa é uma das formas pelas quais os atores políticos buscam obter credibilidade. A busca por credibilidade se faz por meio do exercício, do traballho, do esforço despendido por aqueles/as que se manifestam pela linguagem na construção de uma identidade discursiva capaz de apresentá-los/las como indivíduos engajados e comprometidos com as questões femininas. Isso é também observado no seguinte trecho do documento complementar selecionado para compor os dados desta reflexão:

(...) recomendamos a mobilização em torno de projetos e programas que tenham implicações positivas na redução das condições sociais desfavoráveis ao pleno desenvolvimento das mulheres e de sua capacidade como cidadãs ativas me nosso processo econõmico, político, social. (...) sugerimos amplo debate me torno da PEC 385, de 2001, que inclui milhares de donas de casa no sistema de proteção social de 1 (um) salário mínimo (...). Propomos a criação de uma Comissão especial destinada a efetuar estudo sobre proposições que dispõem sobre trabalho/emprego doméstico em tramitação nesta Casa (...). Defendemos a aprovação de projetos que garantam (...) (Relatório Final - Seminário Internacional: Por um Brasil sem desigualdades, p.51).

Em estudo anterior sobre discurso parlamentar, representação social feminina e ethos político, voltado para as categorias dos tempos do mundo narrado e do mundo comentado, concluo que o texto em análise, produzido igualmente no espaço de poder e de força do Parlamento Nacional, volta-se mais vivamente para a instância política que o constitui. Numa atitude de minimizar os efeitos da dura e cruel realidade que envolve a instância cidadã representada no evento comunicativo em foco, particularmente a sua parcela feminina, os ouvintes são levados a se sentirem resguardados no agir parlamentar. Tal afeito, conforme asseguro naquele momento, resulta em mecanismo configurador da forma pela qual o parlamentar constrói uma imagem positiva de si e do poder executivo, valendo-se de um ethos dito pré-discursivo (Barros, 2009a). Sugiro, a partir daí, que os tempos comentados e narrados devam ser vistos enquanto elementos desencadeadores de processos compreendidos como formas de ação sobre os sujeitos envolvidos nas práticas sociais discursivas. 
Com base nas ideias tecidas até o presente momento, pode-se afirmar que tudo aquilo que diz respeito ao universo social feminino vai assumindo, ao longo da produção dos discursos parlamentares, um valor que transforma aquilo que é dito em instrumento útil à obtenção dos lucros nesse mercado das formas simbólicas. Ressalte-se que o mercado da política, segundo Bourdieu (1989:66) é um dos menos livres que existe.

\section{Identificação social e espaço político}

Nos estudos discursivos, falar sobre identificação social equivale a dizer que, por um lado, as trocas verbais ou interações discursivas são indissociáveis da influência que os interlocutores desejam exercer uns sobre os outros, tal como se constatou acima ao proceder a análise da ação regulatória dos textos sobre os atores sociais que neles aparecem circunscritos. Por outro lado, considerando os espaços sociodiscursivos em que o falante se manifesta, equivale, também, a dizer que a identificação social está ligada à distribuição preestabelecida de papéis para o locutor.

Isso significa que a autoimagem construída pelo falante, perante aqueles aos quais dirige a sua fala, está ligada ao papel social por ele exercido num determinado contexto situacional (campo). Alguns estudiosos, ao situarem o ethos no ato de enunciação, costumam se referir a um ethos dito "pré-discursivo" ou "prévio" e a um ethos dito "discursivo", que tem a ver com a própria atividade linguageira do falante. Enquanto o primeiro está ligado ao estatuto do locutor e à questão de sua legitimidade, ou seja, ao processo de legitimação de sua fala, o segundo está ligado às coerções da situação de comunicação que se lhe impõem².

Ao comentarem a investigação social de cunho qualitativo, Bauer, Gaskell; Allum (2002:17-18) cunham os termos: campo de ação, campo de observação ingênua e campo de observação sistemática para

2. Em estudo específico sobre a questão de gênero social feminino em pronunciamentos levados à tribuna parlamentar (Barros, 2009a, 2009b, 2012a, 2012b), tenho encontrado espaço fértil de debate em torno do funcionamento sociodiscursivo, bem como, persuasivo, da linguagem relativamente ao espaço de força e poder do Parlamento Nacional. 
descreverem situações sociais, respectivamente, em que os sujeitos envolvidos são os atores sociais, os espectadores, ou representam aqueles que manifestam interesse pela situação ou acontecimento.

Assim, no caso específico aqui apresentado, os sujeitos do campo de ação atuariam diretamente na situação social, enquanto os do campo de observação ingênua pensariam e experienciariam o dito, ou ação comunicativa, como se eles próprios estivessem agindo pela linguagem ou fossem elementos constituintes do jogo da linguagem. Devido à sua lealdade para com um dos partidos, bancada, tendência política e movimento social, pensariam e sentiriam o acontecimento dentro de uma perspectiva partidária. Os sujeitos do terceiro campo representariam aqueles que, assim como a própria pesquisadora - elemento central para o sentido construído na pesquisa qualitativa - não têm envolvimento direto com partidos, bancadas ou movimentos sociais e se interessam por questões políticas em geral. Ao pesquisador social cabe, conforme salientam os autores mencionados, investigar não só a natureza do acontecimento, mas também a natureza do campo de ação e dos espectadores.

A investigação de cunho qualitativo prevê, portanto, que o pesquisador social deve investigar não só a natureza do acontecimento, mas também a natureza do campo de ação - que diz respeito aos atores sociais - e do campo de observação ingênua - que diz respeito aos espectadores. Conforme destacado anteriormente, os sujeitos do campo de ação atuam diretamente na situação social, enquanto os do campo de observação ingênua pensam e experimentam o dito, ou ação comunicativa, como se eles próprios estivessem agindo pela linguagem, se posicionando como elementos constituintes do jogo da linguagem.

O ethos é uma estratégia do discurso político que coloca em cena os elementos constitutivos do jogo da linguagem. Enquanto meio discursivo através do qual se torna possível influenciar o auditório, o ethos consolida-se no jogo discursivo configurador das práticas linguísticas que o atualizam. Nesse sentido, a análise da categoria ethos exige, igualmente, a análise da categoria phatos. Quando Aristóteles propôs a tríade logos, ethos e phatos, determinou que, enquanto o primeiro está para o domínio da razão e torna possível convencer, os dois últimos compreendem o domínio da emoção e tornam possível persuadir 
emocionando. Sendo as paixões representações que visam a definir a identidade do sujeito relativamente a outrem (Meyer, 2000:XLVII), as análises que seguem se destinam a perpassar algumas das grandes paixões determinadas por Aristóteles, de modo que se possa revelar a imagem que os/as parlamentares constroem de si frente às crenças e aos valores atribuídos àqueles que os ouvem.

Examinemos de maneira detalhada cada um dos nove excertos selecionados para compor o segundo bloco de dados submetidos à análise.

Excerto (1): A luta de emancipação das mulheres é permanente e cotidiana (...). O desafio da igualdade de gênero merece de nós, homens, maiores reflexões (...). A discriminação é ainda mais perversa quando analisamos a situação da mulher negra (...). Tenho acompanhado a luta das mulheres e vejo que, somente com a implementação de políticas (...).(D.P.1 deputado PT-BA).

Só se pode falar de emancipação de um indivíduo posicionando-o frente a outros já emancipados. Sendo assim, no enunciado: "A luta de emancipação das mulheres é permanente e cotidiana (...)", retrata-se não apenas um aspecto da identidade social feminina, mas também um aspecto da identidade social masculina. Ao caracterizar a luta feminina por sua emancipação, frente ao masculino já emancipado, como "permanente" e "cotidiana", o parlamentar se volta para as rupturas de identidades que causam indignação nas mulheres. A cólera, na Retórica das Paixões, é vista como "um brado contra a diferença imposta, "injusta' ou como tal sentida" (Meyer, 2000:XLIII). Ao se manifestar frente àqueles que se vêem afrontados por esse estado de coisas, a saber, as mulheres por ele representadas, bem como as deputadas presentes no Plenário Nacional, o parlamentar se mostra consciente da sensação de desprezo que as mulheres experimentam frente às questões de gênero. Sendo assim, o orador se posiciona em seu discurso como "homem do povo" em: "O desafio da igualdade de gênero merece de nós, homens, maiores reflexões", assumindo o fato de que esse assunto costuma ser encarado pela parcela masculina da sociedade com desdém. O intensificador "maiores" marca essa atitude de desdém e desprezo com relação à luta de que as mulheres são partidárias. Nesse passo, o parlamentar se posiciona como sujeito consciente, conhecedor das desigualdades entre 
homens e mulheres em "a discriminação é ainda mais perversa quando analisamos a situação da mulher negra", levando seus interlocutores a acreditarem na possibilidade de obterem o desejado, ou seja, a anulação das diferenças. Essa estratégia lhe serve de instrumento útil à obtenção da calma em seus ouvintes. A calma, na Retórica das Paixões visa a recriar a simetria. Surge daí um sujeito solidário e complacente em "Tenho acompanhado a luta das mulheres e vejo que, somente com a implementação de políticas (...)".

Excerto (2): (...) esta passagem de mais um Dia Internacional da mulher apresenta-se como oportuna ocasião para discutirmos as questões de gênero e ressaltar a luta feminina, visando ao reconhecimento da mulher como ser produtivo, respeitável e sobretudo, igual.(...) É desnecessário lembrar o papel e a importância da mulher na sociedade, a sua capacidade de ação e eficiência demonstradas nas mais diversas atividades, mas é importante destacar aspectos nos quais a sua participação é tímida. (...) Em perspectiva mais ampla, é importante o reconhecimento social da contribuição politica das mulheres (...). Tenho participado da luta feminina e colocado o meu mandato a sua disposição (...). (D.P.10 deputado PSB-PE).

Só se pode falar de reconhecimento social das mulheres se as confrontarmos com aqueles indivíduos já reconhecidos socialmente. Sendo assim, semelhantemente ao excerto (1), no excerto (2) o parlamentar se posiciona em seu discurso como sujeito conhecedor das desigualdades sociais e econômica estabelecidas entre os gêneros masculino e feminino. As modalidades apreciativas "é desnecessário lembrar; $e ́$ importante destacar; é importante o reconhecimento", realizadas por meio de predicativos cristalizados, contribuem para destacar a natureza interpessoal desse seu posicionamento que, entre outros fatores, voltase para a descoberta das necessidades, dos anseios e desejos alheios. $\mathrm{O}$ favor na retórica aristotélica é uma concessão de algo à alguém muito necessitado. Aquele que possui concede ao necessitado, não em troca de alguma coisa, nem com o fim de obter alguma vantagem pessoal. Nesse sentido, a obsequiosidade é uma resposta a outrem, atende à sua pretensão, ao seu caráter passional. No jogo especular da troca verbal, o mandato parlamentar, em "tenho participado da luta feminina e colocado o meu mandato a sua disposição", serve para atestar a legitimidade da posição institucional assumida pelo orador nesse 
discurso. Valendo-se do estatuto e do papel que lhe são atribuídos pela situação de comunicação, o parlamentar assume a posição de alguém que reconhece a necessidade do outro, bem como a de alguém que deve exercer a sua função de colocar-se a serviço do outro no discurso. Mais uma vez, deparamo-nos com uma estratégia argumentativa que se presta à obtenção da moderação das paixões.

Excerto (3): (...) Apesar disso, a discriminação contra as mulheres ainda existe. Mesmo possuindo niveis mais elevados de escolaridade, o rendimento médio alcançado pelas mulheres é inferior ao dos homens. (...) E, infelizmente, a discriminação contra as mulheres não é restrita ao Mercado de trabalho.(...) Reconheço a importância da mulher em nossas vidas. (D.P11 deputado PTB-RR).

Não se pode falar de discriminação sem estabelecer uma oposição entre indivíduos socialmente discriminados e não discriminados. A discriminação é geralmente sentida como algo penoso, destrutivo ou arrebatador. Desperta a piedade ou compaixão, o sentimento de pesar sobre sofrimentos imerecidos daqueles que são relativamente próximos. Entretanto, a compaixão, na retórica das paixões, é um sentimento despertado naquele que se vê igualmente ameaçado de sofrer algum mal. Na tradução do texto clássico Retórica das Paixões, é possível ler: "não sentem compaixão os que estão completamente perdidos (...), nem os que se julgam extremamente felizes e são, ao contrário, insolentes, porque se crêem ter todos os bens, evidentemente também pensam que nenhum mal pode atingi-los" (Aristóteles, 2000:53).

No enunciado em análise, demonstrar desprezo pela condição da mulher, enquanto ser discriminado, bem como se acomodar perante esse fato, é compactuar com um estado de coisas que pode desestabilizar a sua forma de vida e a dos outros aos quais se refere. Notemos que, em "reconheço a importância da mulher em nossas vidas", o parlamentar se apresenta em primeira pessoa, incluindo-se naquilo que enuncia, assumindo a posição de alguém que se sente igualmente afetado. Ao admitir como verdadeira, legítima, boa ou digna de admiração a influência exercida pela mulher sobre a sua vida e a dos seus interlocutores, o parlamentar assume uma posição de sujeito que se sente grato e agradecido. 
Passemos à análise do próximo excerto, atentando-se para a confluência dos três modos de fabricação do discurso político.

Excerto (4): Hoje, dia 8 de março, defendo as reivindicações das mulheres neste pronunciamento de apoio à luta das brasileiras. Entendo que a própria imprensa, que muitas vezes tem posturas machistas durante o ano inteiro, imagina que, ao fazer meras publicações sobre a questão da mulher neste dia, está se redimindo do seu papel na história do nosso País. (D.P. 7 deputado PT-PR).

Observe-se que o excerto é construído com base nas três instâncias ou "lugares de fabricação do discurso político: um lugar de governança, um lugar de opinião e um lugar de mediação" (Charaudeau, 2006:55). Segundo preconiza Charaudeau (2006), no primeiro desses lugares se situa a instância política ao lado da instância adversária; no segundo, encontra-se a instância cidadã e, no terceiro, a instância midiática. É possível constatar que o parlamentar se vale de uma manobra argumentativa que recai sobre a legitimidade de decisão e ação conferida à instância política e sobre a legitimidade do papel de informante da instância midiática e, de tabela, regulador da opinião pública. Há, portanto, aí, a vontade do orador de afastar qualquer sentimento de insatisfação que possa surgir por parte da instância cidadã com relação ao papel social desempenhado pelo parlamento. O parlamentar busca, assim, gerir supostos conflitos de opinião acionados pela mídia, subestimando e/ou questionando a forma de agir da instância midiática. Repete-se, aqui, o interesse do parlamentar em acalmar os ânimos daqueles para os quais o seu discurso é dirigido.

Essa mesma forma de seduzir o auditório pode ser encontrada no excerto que segue:

\section{Excerto (5): (...) em homenagem ao Dia Internacional da Mulher queremos não só nos solidarizar com a classe feminina celebrando suas conquistas, apoiando suas lutas e repugnando a violência e a discriminação que ainda a penalizam como também chamar atenção para a explora- ção excessiva e abusiva da imagem da mulher pela mídia. (D.P. 12 deputado PT-ES)}

Não se pode falar de solidariedade sem que haja reconhecimento de injustiças praticadas contra o outro. O sentimento de solidariedade 
surge de um posicionamento de consternação frente às mazelas do outro. Mostra-se solidário aquele que se posiciona frente a fatos e acontecimentos considerados abusivos e improcedentes. Guiada por um sentido moral, a solidariedade vincula o indivíduo às causas, aos sentimentos e valores alheios. Temos aqui mais um exemplo em que o orador constrói para o parlamento e, consequentemente, para si uma imagem de redentor.

No excerto (6), mesmo que o sentimento de cólera e indignação sejam contundentes no pronunciamento do parlamentar, sem destoar dos outros discursos produzidos na Câmara, o que se põe em jogo é a tentativa do enunciador (instância política), que se posiciona perante seus/suas colegas parlamentares (instância adversária), de suscitar no enunciatário (instância cidadã) uma imagem positiva de engajamento, envolvimento e compromisso com o padecer feminino.

Excerto (6): Quero , em nome do meu partido, o Partido Liberal (...) falar do choque e da indignação que sempre me provoca o conhecimento de que, até hoje, alguns setores da sociedade teimam em fazer da discriminação contra a mulher um meio para se beneficiarem (...). É impressionante, Sr. Presidente, que em pleno século XXI exista quem impeça a promoção das suas funcionárias, mantendo-as em postos inferiores e mal remuneradas e ainda justifique a atitude com argumentos extraídos dos piores clichês machistas conhecidos. (...) Algumas pessoas pensam equivocadamente que o Brasil está imune à intolerância contra os direitos da mulher, mas o dia-a-dia mostra que isso não é verdade. Reparemos na profusão de assuntos abordados corriqueiramente aqui mesmo, na Câmara. Para citar apenas 2, a feminização da pobreza e o Estatuto da Mulher são temas que estão sendo discutidos nesta Casa. (...) venho reiteradamente à tribuna chamar a atenção dos nobres pares para a nossa iniciativa que instituiu 2004 como o Ano da Mulher. (D.P.13 deputado PL-TO).

O lugar social ocupado pelo parlamentar parece lhe conferir autoridade em manifestar-se enquanto líder inconteste na condução dos desfavorecidos, a saber, a parcela feminina de seus representados, visando ao bem-estar comum. Mais uma vez, é o espírito de solidariedade que se nos revela na voz consensual do parlamentar.

Outro enunciado que suscita compaixão é o que destacamos no seguinte excerto: 
Excerto (7): Infelizmente, a melhora no nível de instrução não tem permitido a elas receber salários semelhantes aos dos homens. Isso precisa ser revisto (...). (...) infelizmente muitos preconceitos resistem a essa luta e ainda encontramos falta de respeito aos direitos da mulher (...).(D.P. 9 deputado PL-ES).

Atitudes preconceituosas costumam partir daqueles que se vêem distanciados das necessidades e anseios alheios. A atitude de indignação do orador frente ao fato exposto demonstra a sua compaixão por aquelas que sofrem e exigem seus direitos de cidadã. Os advérbios modais servem de elemento configurador do desgosto experimentado pelo parlamentar. Esse efeito de sentido se estende aos excertos (8) e (9).

Excerto (8): Felizmente, o Governo Federal mostrou-se sensibilizado com essa triste e lamentável realidade. Por isso, anunciou (...) que entrará em vigor em aproximadamente 30 dias, a regulamentação de uma lei que obriga hospitais e postos de atendimento médico a comunicar à polícia a ocorrência de internação de mulheres vítimas da violência. Ainda bem, porque é sabido que a cada 4 minutos uma mulher é agredida dentro de casa.. (D.P. 14 deputado PP-RJ).

Excerto (9): As mulheres do Brasil são tratadas como mercadorias por estrangeiros inescrupulosos! Precisamos tentar mudar essa situação. (...) Precisamos mudar o conceito que diversos países têm sobre o Brasil: país de mulher fácil, país da prostituição, bordel de belas praias. (...) É necessário também que essas mulheres (...) tenham acesso à educação, que, acredito, evita a exploração. Lutemos contra essa cruel exploração . (D.P. 15 deputado PTB-RR).

Cada um dos fragmentos de discurso analisados nas duas subseções acima demonstra que os/as parlamentares se posicionam em seus discursos a partir de uma atitude de sujeitos conhecedores dos males que afetam a parcela feminina da sociedade. Posicionam-se, portanto, como sujeitos piedosos e solidários.

No que concerne aos significados identificacionais, não foram constatadas diferenças significativas nos modos de fabricação do discurso por parlamentares homens ou mulheres. Isso pode significar que, no interior de dada rotina social, a construção subjetiva das identidades dos falantes expressa, por sua vez, na materialidade das 
práticas linguístico-discursivas situadas, tende a seguir uma série de estratégias discursivo-persuasivas que automatizam parte das autorrepresentações humanas. Assunto dessa natureza exige, a meu ver, discussão pormenorizada sobre as condições de apropriabilidade dos atos de linguagem.

\section{Palavras finais}

As análises empreendidas neste artigo permitiram identificar posições ideológicas assumidas pelos/as parlamentares, ao se manifestarem no espaço enunciativo de que fazem parte. O modo como cada um dos enunciadores se manifesta na Tribuna da Câmara Federal está intimamente ligado a ajustes intersubjetivos que se processam em função do tratamento do tema "mulher" na prática discursiva parlamentar. Categorias linguísticas, tais como as modalidades epistêmicas, deônticas e apreciativas; nominalização, intensificador semântico; verbos de natureza mental como: reconheço, defendo, entendo, na primeira pessoa, demonstrando governança; advérbios modais, bem como categorias tomadas da retórica aristotélica, tais como calma, cólera e favor, mostraram-se propícias à identificação de posicionamentos intersubjetivos de engajamento.

A reflexão, levada a cabo até o presente momento, permite afirmar que a prática discursiva parlamentar sofre influências do contexto institucional em que os textos são produzidos. Vimos, ainda, que tudo aquilo que diz respeito ao universo social feminino, de alguma maneira, reveste-se em instrumento útil ao agir parlamentar. Esse agir, configurado na prática discursiva parlamentar sustenta, apoia e contribui para o funcionamento e ação das ideologias sobre o mundo da vida daquelas que se vêem nela representadas. Isso suscita a ideia de que o lugar social a partir do qual os sujeitos de linguagem se manifestam condiciona suas ações discursivas consolidadas, por sua vez, em estratégias interpessoais específicas.

Arremato este artigo com a clara convicção de que as categorias retóricas, a sintaxe, a seleção léxica, o estilo e registro configuram elementos constitutivos do controle exercido pelo contexto institucional de produção textual/discursiva. 
Recebido em abril de 2013

Aprovado em abril de 2015

E-mail:

decbarros@uem.br

\section{Referências Bibliográficas}

Aristóteles. 2000. Retórica das Paixões. Trad. do Grego: Isis Borges B. da Fonseca. Prefácio Michel Meyer. São Paulo: Martins Fontes.

BARros, D. E. C. 2009a. Entre o narrar e o comentar: a prática discursiva parlamentar. Anais do XIX Seminário do CELLIP - Pesquisa em Língua e Cultura na América Latina. Cascavel: UNIOESTE, p. 1-8. 2009b. A gramática como testemunho do ethos discursivo parlamentar: ele oculta, ela desvela. Cadernos de Linguagem e Sociedade, v. 10, n.2, p.13-31. Disponível em: http://periodicos.unb. br/index.php/les/article/view/1195/854. Acesso em: 15 abr. 2015.

2012a. Argumentação e linguagem: da retórica à concepção de discurso como prática social. Desenredo, v.8, n.2, p. 95-111. Disponível em: http://www.upf.tche.br/seer/index.php/rd/article/ view/2917/1984. Acesso em: 15 abr. 2015.

2012b. Atuação política feminina e identidades de gêneros: um enlace analítico entre a mídia, o parlamento e a sociedade. Encontros de vista, jul./dez. p. 1- 13. Disponível em: http://www. encontrosdevista.com.br/Artigos/artigo_1_10.pdf. Acesso em: 15 abr. 2015.

Bauer, Martin W.; Gaskell, G. \& Allum, N. C. 2002. Qualidade, quantidade e interesses do conhecimento. In: BAUER, M. W. \& Gaskell, G. (eds.) Pesquisa qualitativa com texto, imagem e som: um manual prático. Trad. Pedrinho A. Guareschi. Petrópolis: Vozes, p. 17-36.

Bourdieu, Pierre. 1989. O poder simbólico. Rio de janeiro: Editora Bertrand do Brasil.

Charaudeau, Patrick. 2006. Discurso político. Trad. Dílson Ferreira da Cruz e Fabiana Komesu. São Paulo: Contexto.

Fairclough, Norman. 2001. Discurso e mudança social. Coordenadora da trad. Izabel Magalhães. Brasília: Editora UnB. Original em Inglês: Discourse and social change. Cambridge: Polity Press, 1992. 2003. Analysing discourse: textual analysis for social research. London/New York: Routledge. 
FoucAult, Michel. 1994. What is enlightenment?. In: Rabinow, P. (ed.). Michel Foucault: essential works - vol 1 (ethics). Harmondsworth: Peguin, p. 303-319.

HallidAY, M. A. K. 1976. Estrutura e função da linguagem. In: Lyons, J. (org.). Novos Horizontes em Lingüística. Trad. Geraldo Cintra et. al. São Paulo: Cultrix/ed. da Universidade de São Paulo.

Meyer, Michel. 2000. Prefácio. In: Retórica das Paixões. Trad. do Grego Isis Borges B. da Fonseca. São Paulo: Martins Fontes, viii.

Meurer, José Luiz. 2004. Ampliando a noção de contexto na lingüística sistêmico-funcional e na análise crítica do discurso. Linguagem em Discurso, 4 (Número Especial - Análise Crítica do Discurso), p.133-157.

Relatório final da Comissão Externa da Feminização da Pobreza do Brasil e Seminário Internacional "Por um Brasil sem desigualdades". 2004. Brasília: Câmara dos Deputados, Coordenação de Publicações. 